This item was submitted to Loughborough's Research Repository by the author.

Items in Figshare are protected by copyright, with all rights reserved, unless otherwise indicated.

\title{
Heterogeneous substrate microstrip antenna with enhanced bandwidth
}

PLEASE CITE THE PUBLISHED VERSION

http://dx.doi.org/10.1109/LAPC.2013.6711885

PUBLISHER

(c) IEEE

VERSION

AM (Accepted Manuscript)

LICENCE

CC BY-NC-ND 4.0

REPOSITORY RECORD

Bukhari, Syed S., and W.G. Whittow. 2019. "Heterogeneous Substrate Microstrip Antenna with Enhanced Bandwidth”. figshare. https://hdl.handle.net/2134/14383. 
This item was submitted to Loughborough's Institutional Repository (https://dspace.lboro.ac.uk/) by the author and is made available under the following Creative Commons Licence conditions.

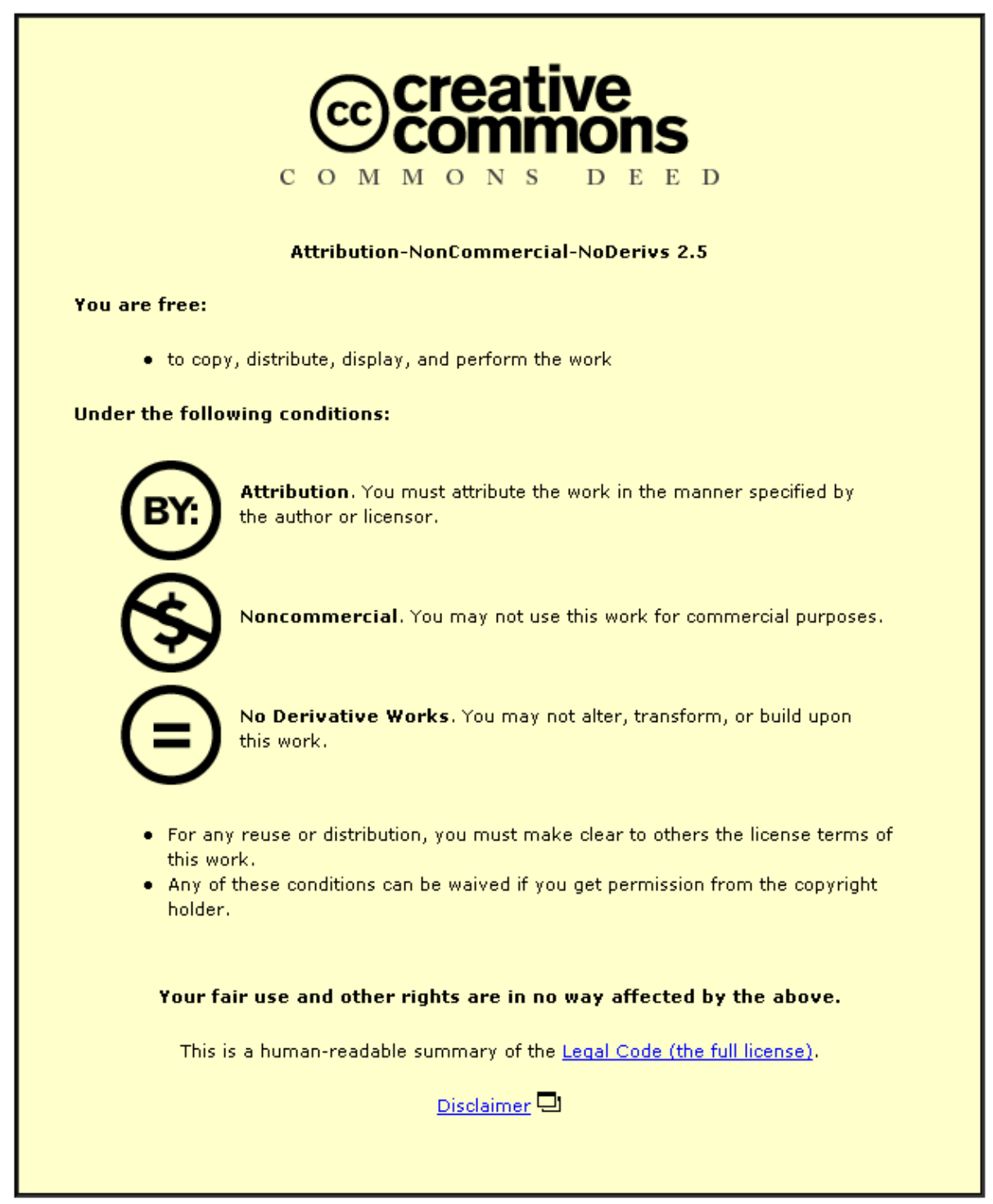

For the full text of this licence, please go to: http://creativecommons.org/licenses/by-nc-nd/2.5/ 


\section{Heterogeneous Substrate Microstrip Antenna With Enhanced Bandwidth}

\author{
S. S. Bukhari \\ School of Electronic, Electrical and Systems Engineering \\ Loughborough University, \\ Loughborough, LE11 3TU, UK \\ s.s.bukhari@lboro.ac.uk
}

\begin{abstract}
A heterogeneous substrate is designed when the permittivity of a substrate is changed as a function of location. Due to non-uniformity of the electric fields in a patch, loading of different areas with heterogeneous dielectrics can change behavior. In this paper heterogeneous substrates are employed to increase the bandwidth of a patch by combining its first and second resonance.
\end{abstract}

Keywords- microstrip antennas, heterogeneous substrates, enhanced bandwidth

\section{INTRODUCTION}

Microstrip antennas are light weight, low profile, conformal structures which are easily integrated with other elements of the circuitry. These structures however have inherently a narrow bandwidth which limits their use [1]. Various designs like planar inverted $\mathrm{F}$ antennas, stacked patches, defected ground planes and parasitic elements have been proposed for increasing the bandwidth of microstrip antennas [1-6].

Heterogeneous substrates yield different values of permittivity at different locations in a substrate and are employed to enhance the electromagnetic performance of microstrip antennas [7]. These substrates have been used for lowering the effective dielectric index of the substrates; suppress the surface waves emanating from the patch; reduce the insertion loss of filters; improve the radiation pattern of a patch and decrease mutual couplings among the antenna elements of an array [8-12]. These substrates are usually synthesized by drilling holes inside a substrate, removal of a section of the substrate and embedding a material with different dielectric properties inside the substrate [8], [13-14]. Recently, it was proposed that additive manufacturing techniques and 3-D printing can also be used for manufacturing heterogeneous substrates [15], [16].

The electric fields of a patch vary along its surface and introducing non-homogeneity in the substrate at different locations perturbs the behavior of the patch differently. The electric fields are generally highest at the radiating edges for the resonant frequency of the patch, thus changing the permittivity locally, in this region affects the performance of the patch the most [7]. A larger change in the permittivity of

\author{
W. G. Whittow \\ School of Electronic, Electrical and Systems Engineering \\ Loughborough University, \\ Loughborough, LE11 3TU, UK \\ w.g.whittow@1boro.ac.uk
}

the introduced dielectric loading at the same location produces a larger effect hence just like the location of non-homogeneity, the dielectric properties of this newly introduced material are also very important and need to be taken into account while tailoring the response of the radiator, in order to get the desired results. By carefully controlling the permittivity and location of the introduced dielectric inside the substrate, the first and second resonances of a rectangular microstrip antenna are combined leading to an increase in the overall bandwidth of the structure.

\section{ANTENNA GEOMETRY}

The patch is placed on a $76 \times 76 \mathrm{~mm}^{2}, 3.5 \mathrm{~mm}$ thick Rogers RU-3003 substrate, having a loss tangent of 0.013 and relative permittivity of 3 . Slots have been cut inside the substrate and are symmetrical along the edges of the patch. Slots along yaxis are have a length of $38 \mathrm{~mm}$, a width of $6 \mathrm{~mm}$ and are filled with Rogers-RT/Duroid-5880, a material having a relative permittivity of 2.2 and a loss tangent of 0.0009 .

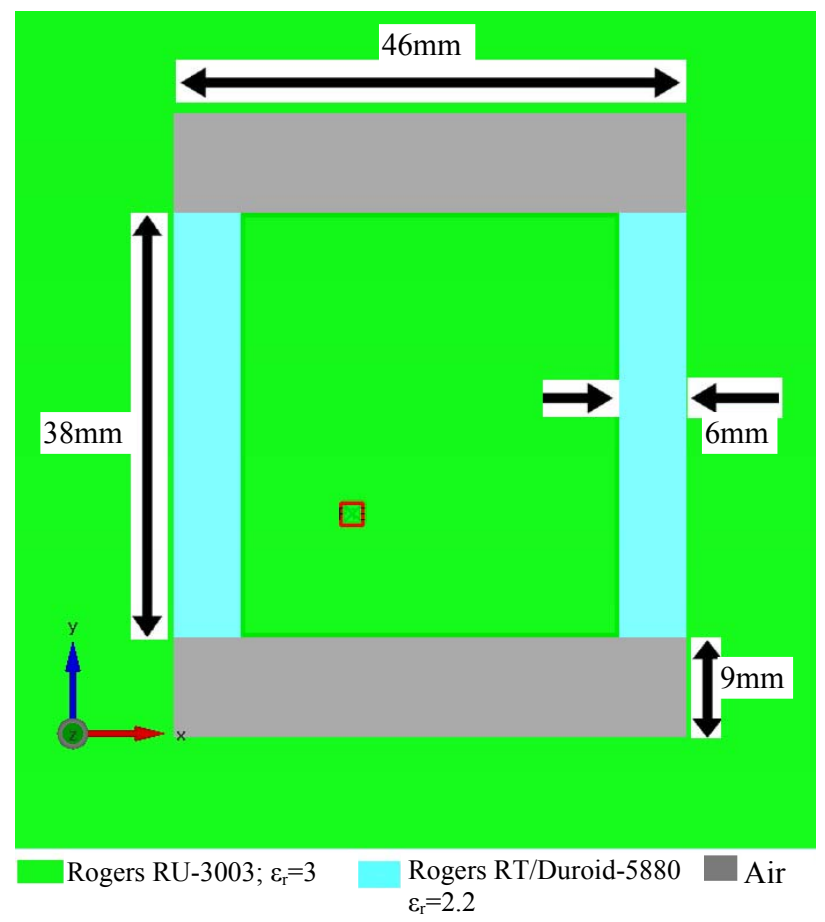

Figure 1: Heterogeneous substrate synthesized by cutting slots 
Along $\mathrm{x}$-axis the slots are $46 \mathrm{~mm}$ long, $9 \mathrm{~mm}$ wide and airfilled. Figure 1 illustrates the substrate and the embedded slots along with their dimensions and local relative permittivity.

The impedance matching is dependent on the feed position for a probe feed. In this design the feed has to be placed in such a way that a better match for both resonances is obtained. The two resonances are from the perpendicular edges of the patch so the feed is off-set with respect to both axes. The patch is $47 \mathrm{~mm}$ in length (along y-axis) and $40 \mathrm{~mm}$ in width (along x-axis) and is shown in Figure 2 along with the position of the feed.

\section{RESULTS AND DISCUSSION}

The bandwidth of a microstrip patch is improved by using heterogeneous substrates. These substrates are prepared by cutting slots of different size and relative permittivity in the substrate. The underlying principle is that the electric fields of a patch are non-uniformly distributed therefore introducing a non-homogeneity in a substrate at different location under the patch produces different results. The slots introduced in the substrate at the center of the patch where the electric fields are low, produce a very small effect in comparison to the slots at the edges of the patch where electric fields are high therefore by controlling the size, relative permittivity and position of the slots, the resonances from the perpendicular edges of the patch can be combined which increases the bandwidth of the antenna. The Rogers RT/Duroid-5880 filled slots along y-axis affect the second resonance the most whereas the air filled slots along the $\mathrm{x}$-axis have a larger impact on the second resonance. The sizes of both slots are optimized to combine the resonances due to the perpendicular edges of the patch and have a larger bandwidth. Low loss materials have been used for preparing this heterogeneous substrate. The total bandwidth for heterogeneous substrate antenna is approximately $0.19 \mathrm{GHz}$.

Figure 3 and Figure 4 show the electric fields in the heterogeneous substrate patch at both resonances. The first resonance occurs at $2.12 \mathrm{GHz}$ and is due to the edges of the patch oriented along $\mathrm{x}$-axis as indicated by Figure 3 , which shows a high concentration of electric fields around these edges. Figure 4 demonstrates the electric fields at $2.22 \mathrm{GHz}$, the second resonance which is due to the edges of the patch placed along $y$-axis. This concept is reinforced by high values of electric fields along these edges. The return loss for this antenna is shown in Figure 5. The radiation patterns for both resonances in theta and phi planes are shown in Figure 6 and Figure 7.

This antenna is then compared with another antenna which has the exact same physical attributes except for having a homogeneous Rogers RU-3003 substrate. The homogeneous substrate antenna has a $10-\mathrm{dB}$ impedance bandwidth of $0.03 \mathrm{GHz}$, with its first resonance occurring at $1.77 \mathrm{GHz}$. Its second resonance is at $2.02 \mathrm{GHz}$ and the antenna has a $10-\mathrm{dB}$ impedance bandwidth of $0.06 \mathrm{GHz}$ for the second resonance.

In order to keep the resonant frequency of the antenna on a $3.5 \mathrm{~mm}$ thick Rogers RU-3003 substrate the same, the length and width of the homogeneous antenna was reduced to $38 \mathrm{~mm}$ and $32 \mathrm{~mm}$ respectively. This antenna had a resonant frequency of $2.15 \mathrm{GHz}$ and a bandwidth of $0.05 \mathrm{GHz}$. The feed

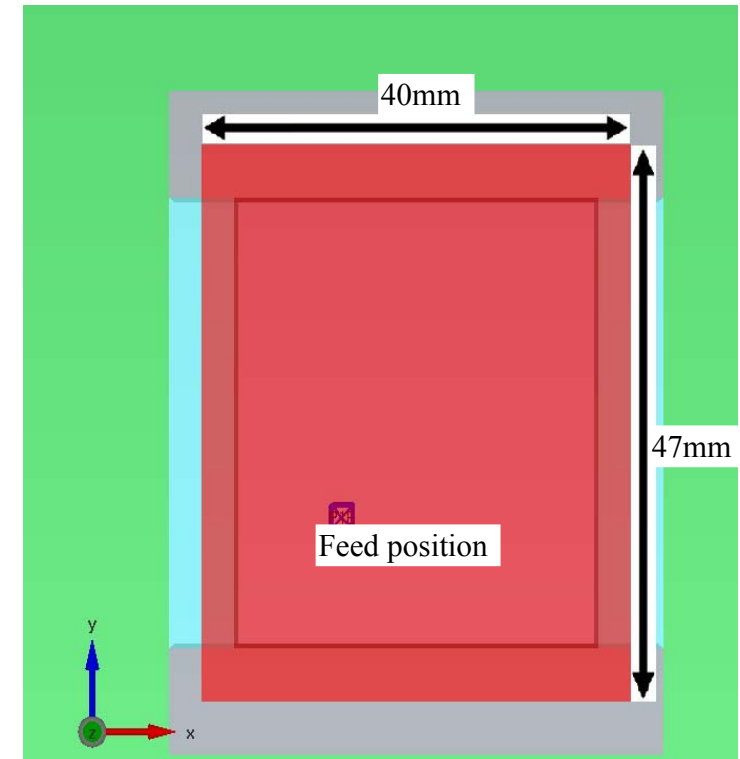

Figure 2: Patch antenna on heterogeneous substrates showing patch dimensions and feed position

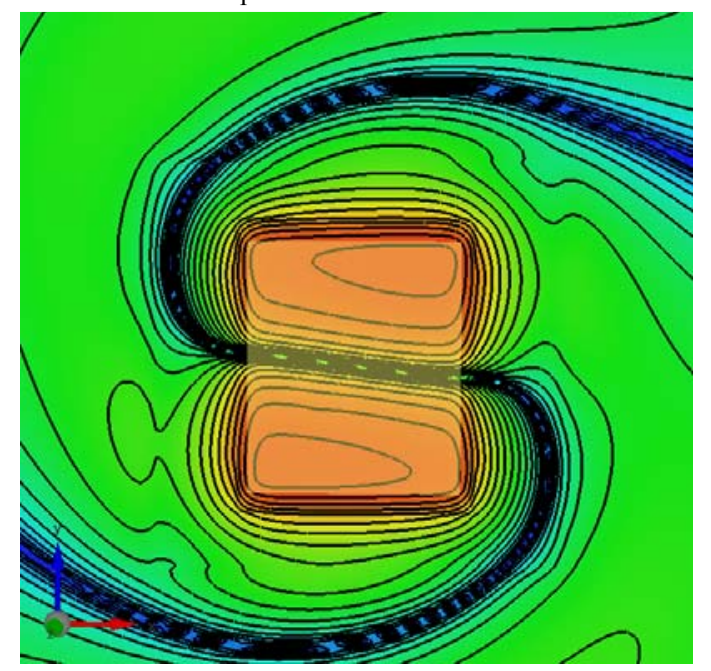

Figure 3: Electric fields at first resonance $(2.12 \mathrm{GHz})$

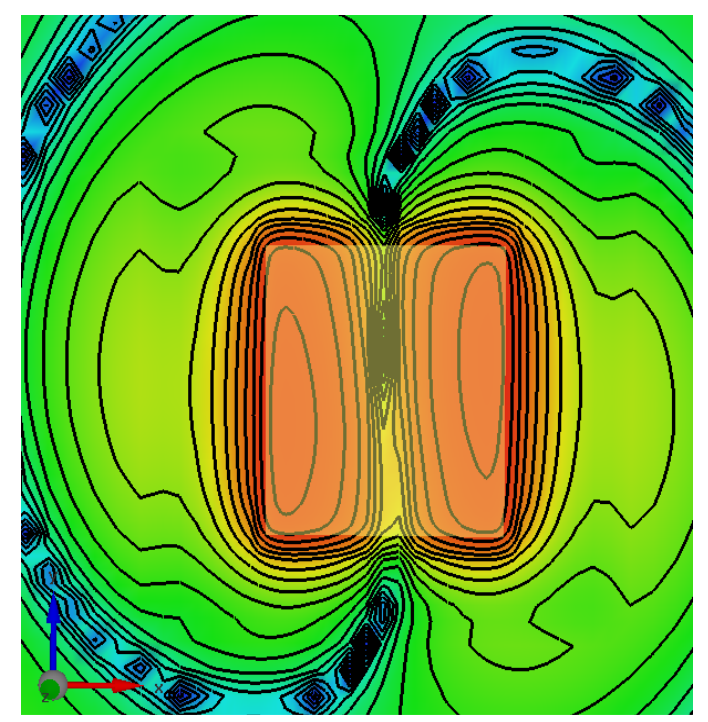

Figure 4: Electric fields at second resonance $(2.22 \mathrm{GHz})$ 
position of this antenna was optimized in order to achieve a better impedance match at the resonant frequency.

All antennas are simulated in EMPIRE XCcEL software which uses finite difference time domain (FDTD) algorithm.

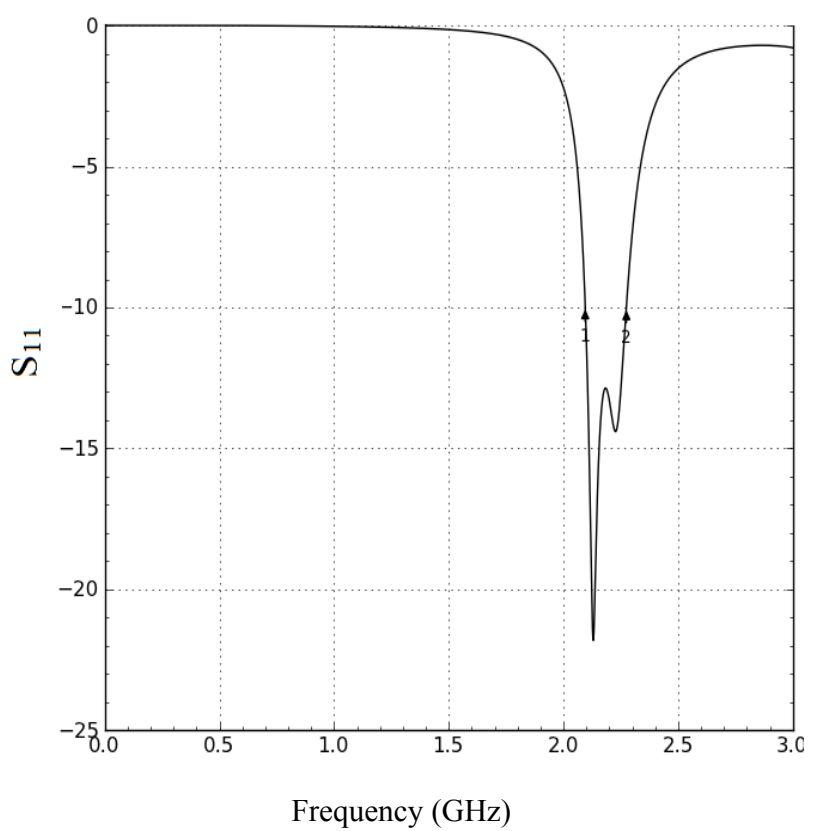

Figure 5: $\mathrm{S}_{11}$ for the heterogeneous substrate patch antenna

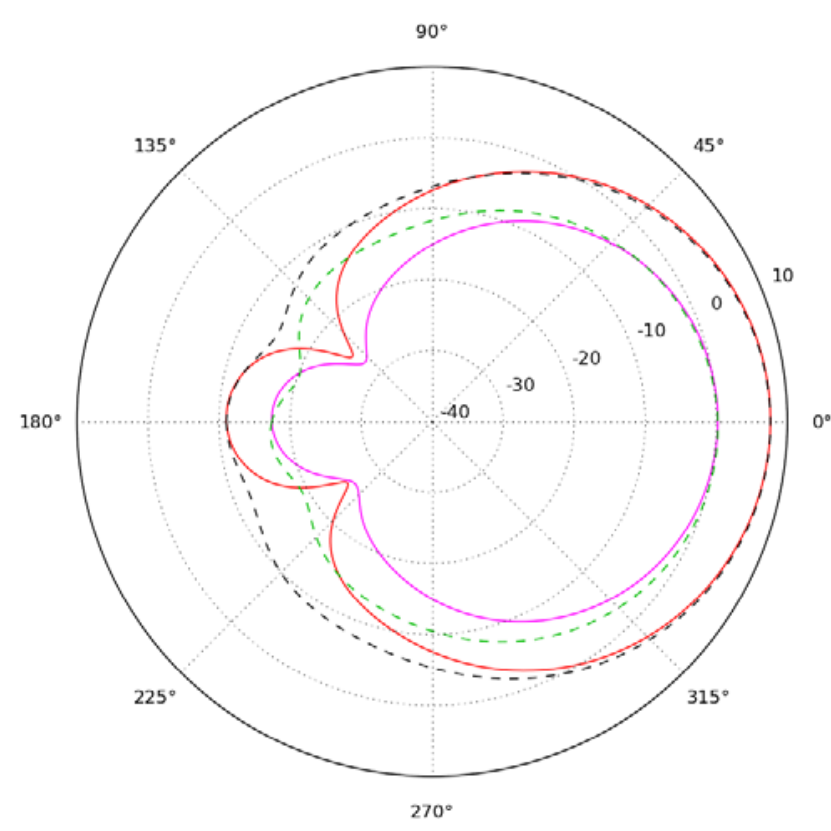

Figure 6: Radiation patterns in both theta and phi planes for heterogeneous substrate patch at $2.12 \mathrm{GHz}$ (first resonance). Dotted lines are for the phi-plane. (Polar plot on $\mathrm{dB}$ scale)

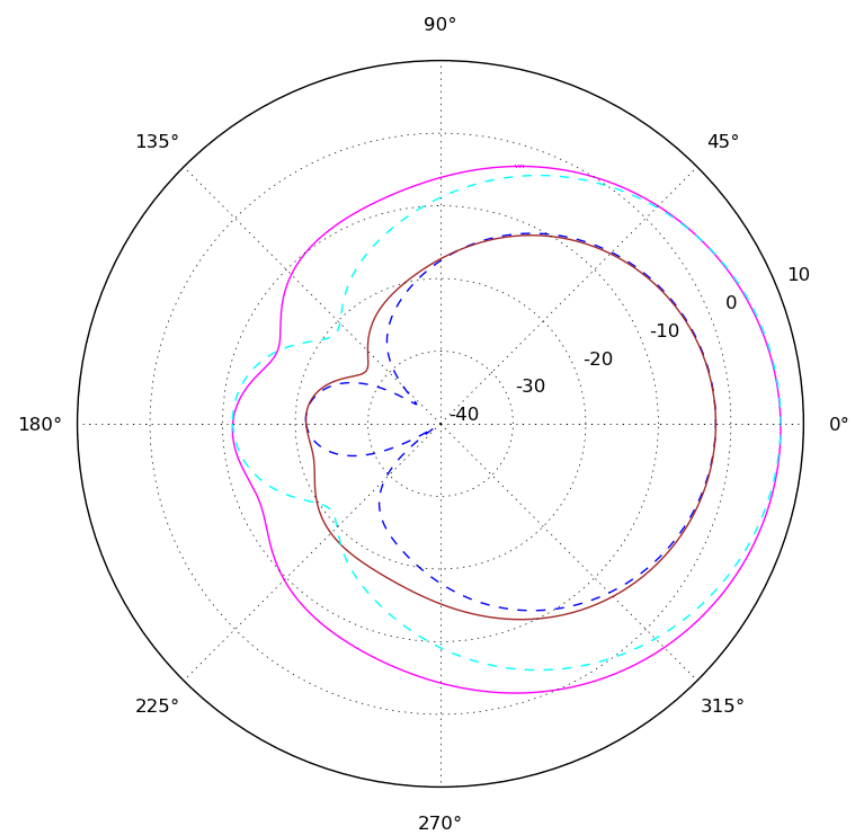

Figure 7: Radiation patterns in both theta and phi planes for heterogeneous substrate patch at $2.22 \mathrm{GHz}$ (first resonance). Dotted lines are for the phi-plane. (Polar plot on $\mathrm{dB}$ scale)

\section{CONCLUSION}

A heterogeneous substrate antenna is proposed for improving the 10-dB impedance bandwidth. Heterogeneous substrate is prepared by cutting slots in a homogeneous substrate block. The electric fields of a patch are non-uniform and by placing the slots of different dielectric index at the perpendicular edges of the patch, the resonances due to both slots are affected differently. These resonances are then brought together to enhance the bandwidth of the proposed antenna.

\section{REFERENCES}

S. D. Targonski, R. B. Waterhouse, and D. M. Pozar, "Design of wide-band aperture-stacked patch microstrip antennas," IEEE Transactions on Antennas and Propagation, vol. 46, no. 9, pp. 1245-1251, 1998.

T. Taga and K. Tsunekawa, "Performance Analysis of a Built-In Planar Inverted F Antenna for $800 \mathrm{MHz}$ Band Portable Radio Units," IEEE Journal on Selected Areas in Communications vol. 5, no. 5, pp. 921-929, 1987.

[3] S. Egashira and E. Nishiyama, "Stacked microstrip antenna with wide bandwidth and high gain," IEEE Transactions on Antennas and Propagation, vol. 44, no. 11, pp. 1533-1534, 1996.

M. J. Ammann and M. John, "Optimum design of the printed strip monopole," IEEE Antennas and Propagation Magazine, vol. 47, no. 6, pp. 59-61, Dec. 2005.

[5] M. J. Ammann and M. John, "Some techniques to improve small groundplane printed monopole performance," in 2007 IEEE Antennas and Propagation International Symposium, 2007, pp. 2825-2828. 
[6] C. Wood, "Improved bandwidth of microstrip antennas using parasitic elements," IEE Proceedings $H$ Microwaves, Optics and Antennas, vol. 127, no. 4, pp. 231-234, 1980.

[7] W. G. Whittow, C. C. Njoku, J. C. Vardaxoglou, and J. Joubert, "Designing multi-band and high bandwidth antennas with heterogeneous substrates," in 2012 IEEE-APS Topical Conference on Antennas and Propagation in Wireless Communications (APWC), 2012, pp. 748-751.

[8] G. P. Gauthier, A. Courtay, and G. M. Rebeiz, "Microstrip Antennas on Synthesized Low Dielectric-Constant Substrates," IEEE Transactions on Antennas and Propagation, vol. 45, no. 8, pp. 1310-1314, 1997.

[9] D. R. Jackson, J. T. Williams, A. K. Bhattacharyya, R. L. Smith, S. J. Buchheit, and S. A. Long, "Microstrip patch designs that do not excite surface waves," IEEE Transactions on Antennas and Propagation, vol. 41, no. 8, pp. 1026-1037, 1993.

[10] X. Gong, T. Smyth, E. Ghaneie, and W. J. Chappell, "High- Q Resonators and Filters Inside Advanced Low-Temperature Co-Fired Ceramic Substrates Using Fine-Scale Periodicity," IEEE Transactions on Microwave Theory and Techniques, vol. 56, no. 4, pp. 922-930, 2008.

[11] J. S. Colburn and Y. Rahmat-Samii, "Patch antennas on externally perforated high dielectric constant substrates," IEEE Transactions on Antennas and Propagation, vol. 47, no. 12, pp. 1785-1794, 1999.

[12] L. P. B. Katehi, "Micromachined microstrip patch antenna with controlled mutual coupling and surface waves," IEEE Transactions on Antennas and Propagation, vol. 49, no. 9, pp. 1282-1289, 2001.

[13] I. Papapolymerou, R. F. Drayton, and L. P. B. Katehi, "Micromachined Patch Antennas," IEEE Transactions on Antennas and Propagation, vol. 46, no. 2, pp. 275-283, 1998.

[14] D. Psychoudakis, Y.-H. Koh, J. L. Volakis, and J. H. Halloran, "Design Method for Aperture-Coupled Microstrip Patch Antennas on Textured Dielectric Substrates," IEEE Transactions on Antennas and Propagation, vol. 52, no. 10, pp. 2763-2765, Oct. 2004.

[15] C. C. Njoku, W. G. Whittow, and J. C. Vardaxoglou, "Effective Permittivity of Heterogeneous Substrates With Cubes in a 3-D Lattice," IEEE Antennas and Wireless Propagation Letters, vol. 10, pp. 1480-1483, 2011.

[16] C. C. Njoku, W. G. Whittow, and J. C. Vardaxoglou, "Simulation Methodology for Synthesis of Antenna Substrates With Microscale Inclusions," IEEE Transactions on Antennas and Propagation, vol. 60, no. 5, pp. 2194-2202, May 2012. 